\title{
The Evolution of Grinding Mill Power Models
}

\section{Raj Rajamani, Pramod Kumar \& Nicolin Govender}

Mining, Metallurgy \& Exploration

An Official International Peer-reviewed Journal of the Society

ISSN 2524-3462

Volume 36

Number 1

Mining, Metallurgy \& Exploration (2019) 36:151-157

DOI 10.1007/s42461-018-0037-3

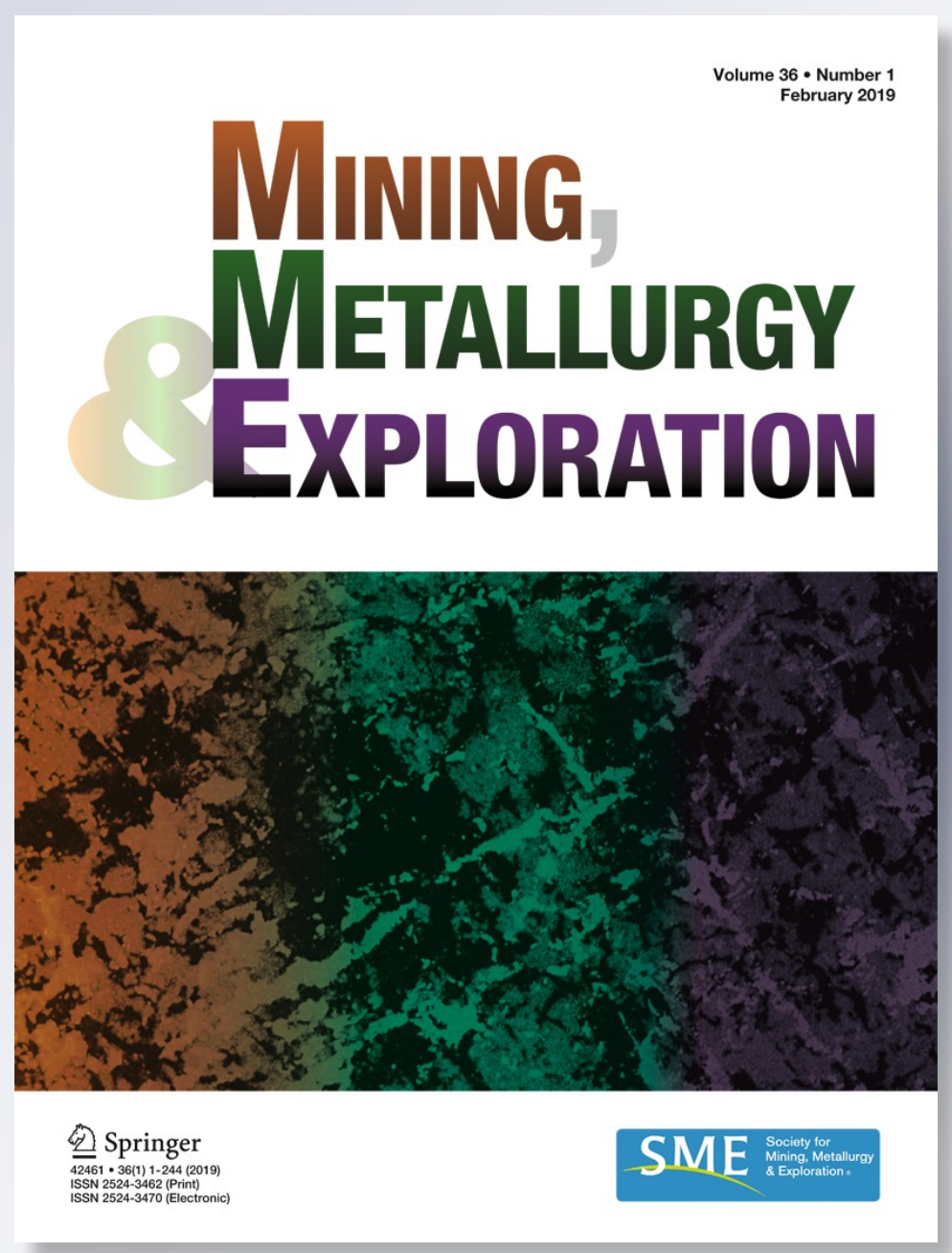

焦 Springer 
Your article is protected by copyright and all rights are held exclusively by Society for Mining, Metallurgy \& Exploration Inc.. This eoffprint is for personal use only and shall not be self-archived in electronic repositories. If you wish to self-archive your article, please use the accepted manuscript version for posting on your own website. You may further deposit the accepted manuscript version in any repository, provided it is only made publicly available 12 months after official publication or later and provided acknowledgement is given to the original source of publication and a link is inserted to the published article on Springer's website. The link must be accompanied by the following text: "The final publication is available at link.springer.com". 


\title{
The Evolution of Grinding Mill Power Models
}

\author{
Raj Rajamani ${ }^{1}$ (D) Pramod Kumar ${ }^{2} \cdot$ Nicolin Govender ${ }^{3,4}$ \\ Received: 15 November 2018 / Accepted: 14 December 2018 / Published online: 30 January 2019 \\ (C) Society for Mining, Metallurgy \& Exploration Inc. 2019
}

\begin{abstract}
Mill power models have been used in a variety of ways in industrial practice since power directly equates to throughput and fineness of ground product. We first start with Hogg-Fuerstenau Power Model and show how this model successfully predicted the power draw of many grinding mills in several mining operations. Then, we show how this model was on the verge of being able to predict the influence of lifter design on power draw. Next, we describe the discrete element model and how it overcame the issues faced by the previous power model. Using a DEM software known as Millsoft, we show the influence of lifter design geometry on power draw and analyze the power draw of rubber lifters versus the steel lifters via several case studies. As years passed, the two-dimensional discrete element model imbedded in Millsoft is superseded by three-dimensional discrete element method. Due to the gigantic computational power of graphic processing units, new computational codes that can do the tumbling motion along the entire length of the mill has come about. Here, we show the predictive capability of Blaze-DEM for ball and SAG mills.
\end{abstract}

Keywords Grinding $\cdot$ Mill $\cdot$ Power $\cdot$ Discrete element method

\section{Introduction}

In a mining operation grinding mill power draw is an essential operating parameter since the energy spent in milling the ore contributes significantly to the cost metal production. Besides, the energy spent per ton of processed in the mill influences the degree of size reduction in the mill. As a result, several mill power models have been published in the last 50 years. Of notable interest is Austin's mill power equation [1] and Morrell's more detailed yet semi-empirical power model [2]. Daniel et al. have described the consolidation of several mill power models [3]. In this manuscript, we focus on one such power model published by Hogg and Fuerstenau [4]. The

Raj Rajamani

raj.rajamani@utah.edu

1 Metallurgical Engineering Department, University of Utah, Salt Lake City, USA

2 Polycorp Limited, Elora, Canada

3 Research Center Pharmaceutical Engineering, Graz, Austria

4 Department of Chemical Engineering, University of Surrey, Guildford, UK extension of this model to autogenous and semi-autogenous model is found in Sepulveda [5].

\section{Hogg and Fuerstenau Mill Power Model}

The balls are carried around with the drum until a point is reached where gravitational forces are just balanced by the centrifugal forces. At this point, balls are released from the shell and they follow a parabolic "free-flight" trajectory and then reenter the ball charge. The point of projection into freeflight starts on the circumference of a circle of radius $g / 2 \omega^{2}$, known as Davis circle.

As shown in Fig. 1, balls in different layers execute a parabolic downward trajectory, and then they reenter the ball mass at locations and continue their upward path. This is a simplified model of the charge motion. The power draw was derived from the kinetic energy contained in these paths. Hogg and Fuerstenau [4] pointed out the following: (1) such an analysis primarily does not take into account the quantity of material (ball filling level) in the mill and (2) the paths indicated in Fig. 1 cannot cross at anytime is incorrect since a ball at the point of collision with the charge from its downward flight may not reenter the charge but flow down the surface of the charge and then reenter the bed. 


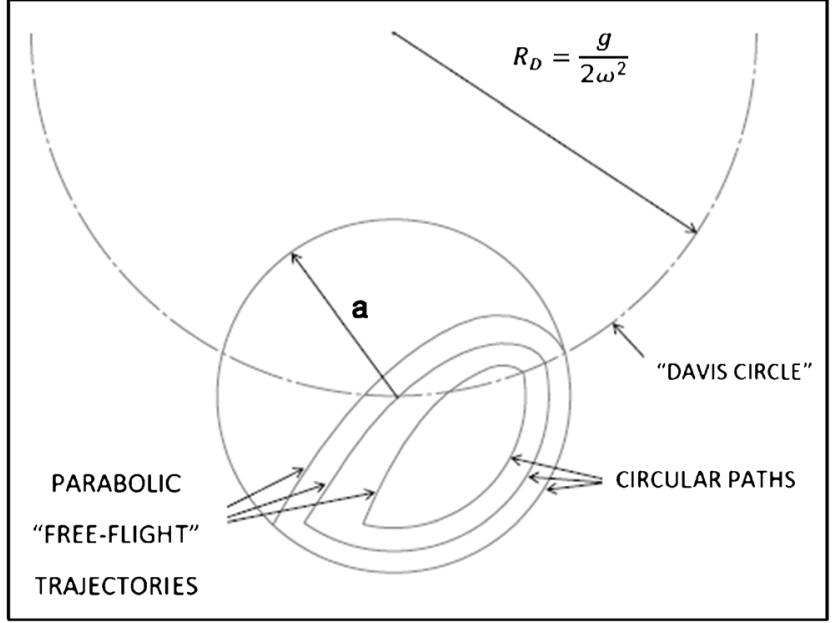

Fig. 1 Free-flight of balls starting at the Davis circle

Hogg and Fuerstenau [4] using an approximate model of the motion of the ball charge derived a simple equation relating mill power to mill dimensions, speed of rotation, and the ball filling level. In this model, it was assumed that the charge consists of two distinct regions: a "static" region where particles do not move relative to the mill shell and a "shear" zone where particles flow down the free surface of the charge. It is further assumed that these two regions are separated by a planar "equilibrium surface" whose inclination is equal to the angle of repose (indicated as $\alpha$ in Fig. 2).

Briefly stated, energy must be supplied to the mill shell to raise the balls in their circular path through the static region of the bed (i.e., moving along with the mill shell) from lower (toe) to the upper part (shoulder). Thus, the potential energy acquired in the static region is simply lost in the shear zone. In

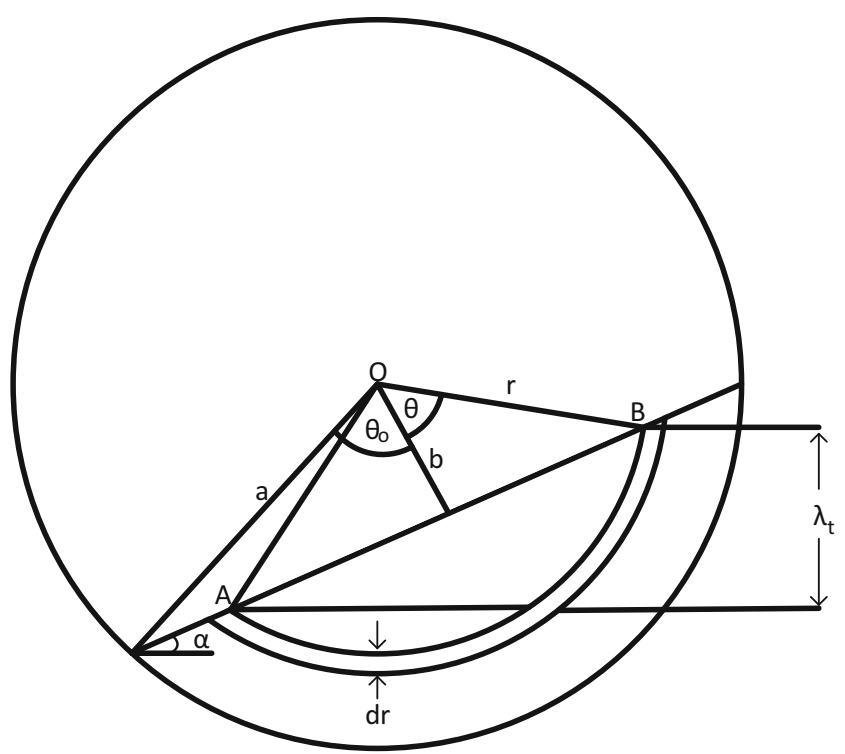

Fig. 2 Ball charge equilibrium surface inclined at the angle of repose this model, the equilibrium surface is inclined to the horizontal line by the angle of repose of the ball charge. Under these conditions, the power is given by

$P=\frac{2}{3} \rho_{\text {app }} \times g^{\frac{3}{2}} \times L \times N_{\mathrm{c}}\left(\frac{D_{\mathrm{m}}}{2}\right)^{\frac{5}{2}} \sin ^{3} \theta_{0} \times \sin (\alpha)$

where $\rho_{\text {app }}$ is the apparent charge density (including voids filled with slurry), $g$ is the gravitational constant, $L$ is the mill length, $N_{\mathrm{c}}$ is the fractional critical speed, $D_{\mathrm{m}}$ is the mill diameter, $\alpha$ is the angle of repose of the ball charge, and $b$ is the distance of the equilibrium surface from the mill center. The angle $\theta_{0}$ is related to the mill filling $J$ by

$J=\frac{\theta_{o}-\sin \left(\theta_{0}\right) \cos \left(\theta_{0}\right)}{\pi}$

Rate of Breakage in Mills The size-discretized population balance model has been the subject of evolution in the 1970s, and by 1990 s, this model has been imbedded in flowsheet simulation software. For instance, MODSIM, USIMPACK, JKSIMMET, and Moly-Cop Tools incorporate the population balance model in a variety of ways to compute mill discharge distribution of ball and autogenous and semi-autogenous grinding mills. Herbst and Fuerstenau [6] made a seminal contribution to the "rate of breakage" parameter used in this model. This key relationship between time rate of breakage and energy input enabled the use of experiments done in a small laboratory mill to study the behavior of plant scale mills.

The size-discretized population balance model is given by

$\frac{d m_{i}(t)}{d t}=-S_{i} \times m_{i}(t)+\sum_{j=1}^{i-1} b_{i j} \times S_{j} \times m_{j}(t)$

where $m_{i}(t)$ is the mass fraction of material in the $i$ th size interval at time $t, S_{i}$ is the size-discretized breakage rate function for the $i$ th interval, and $b_{i j}$ is the size-discretized breakage function, representing the fraction primary breakage product from the $j$ th size interval which appears in the $i$ th size interval.

In a series of tests conducted in a $10 \times 11.5$-in. ball mill at critical speeds 0.53 to 0.90 , ball filling levels 35 to $50 \%$ and particle filling levels 80 to $160 \%$, the authors [7] analyzed the rate of breakage an arrived at the relationship between rate of breakage of size $i$ with power $P$ and particle holdup $H$,

$S_{i}=S_{i}^{E}\left(\frac{P}{H}\right)$

where $S_{i}^{E}$ is a constant dependent only on the hardness or softness of the material in the mill. Since the product of specific power, $P / H$, and time is equal to the specific energy input to the mill, $E$, the population balance model is written in "energy normalized form" as 


$$
\frac{d m_{i}(\bar{E})}{d t}=-S_{i}^{E} \times m_{i}(\bar{E})+\sum_{j=1}^{i-1} b_{i j} \times S_{j}^{E} \times m_{j}(\bar{E})
$$

Equation (4) implies that the evolution of size distribution within the mill is only dependent upon the specific energy in put to the mill. In other words, a large ball mill operating with two orders of magnitude in power and feed rate to the mill exhibits the same breakage regime as that of a laboratory size mill operating at the same energy input. This result is another seminal contribution to come out of Fuerstenau's studies that led to successful scale-up studies. Herbst et al. (1982) proved the scale-up from $10 \times 11.5$-in. ball mill to $30 \times 18$-in. continuous flow mill. In a similar study, Herbst et al. [8] demonstrated successful scale-up from the $10 \times 11.5$-in. ball mill to $14 \times 22$-ft. plant-scale mill. Because of number of such studies, this scale-up procedure is imbedded in Moly-Cop Tool's "Ball Mill Simulation" worksheet.

Now, this energy-based rate of breakage has an implication on grinding regimes within ball mills. In ball mill grinding, it has been well established that grinding of particles occurs within the ball charge mainly due to shearing action of the cascading ball charge. The successful scaleup from a mill diameter as small as $10 \mathrm{in}$. to as large as $14 \mathrm{ft}$. and higher implies the following: the shear energy per unit mass of particles present in the lab mill is similar in magnitude to the shear energy in the cascading regime of a plant mill. This is reasonably possible for medium critical speed of the mill; the static region of the ball mass moves along with the mill shell (in motion) and then after reaching the shoulder region the bed of balls cascade freely and return to the static region at the toe region. Therefore, the shearing action in the cascading region can be similar in both the lab mill and plant mill. It is just that the shear volume and particle mass is just proportional to mill size and hence the energy normalized breakage rate is nearly the same in both mills. This idea was the point of careful examination for one of the authors of the current manuscript, and that was the seed for the birth of the discrete element simulation of charge motion in ball mills $[9,10]$.

Moly-Cop Tools 3.0 has gained wide use in many mining plant operations due to its simplicity and ease of use. The simulation modules are written in Excel worksheet and the 60 or so modules are distributed free of charge. Here, we focus on one of the tools which adapted Hogg and Fuerstenau's model given in Eq. (1) which is imbedded in the module "Mill Power Ball Mills." The model equation is slightly altered for ease of entering data as

$$
\begin{aligned}
P= & 0.238 D^{3.5} \times\left(\frac{L}{D}\right) \times N_{c} \times \rho\left(J-1.065 \times J^{2}\right) \\
& \times \sin (\alpha)
\end{aligned}
$$

In adapting the power formula for ease of use, the MolyCop Tool designers have converted the $\operatorname{Sin} \theta^{3}{ }_{0}$ term in terms of mill filling, $J$, including voids. Because of this tool box, the power equation has seen extensive use in the hands of authors as well as many mines which use this tool package routinely.

\section{The Discrete Element Method}

The mill power models were undergoing several refinements in the 1980s. However, a new method known as the discrete element method, due to Cundall and Strack [11], was sweeping the landscape for the simulation of an assemblage of particles in motion due to external forces. The first application of this method to the prediction of power in tumbling mills is due to Mishra and Rajamani [9]. In this method, the contents of the mill charge, instead of being modeled as a single mass, is given individual identity to each and every ball. The grinding balls are modeled as spheres and the mill shell is modeled as a long cylinder and the exact geometry of the lifter bars is modeled with exact planar dimensions. The key simulation feature is that as the mill shell rotates, it imparts momentum to the spheres that are in immediate contact with the shell, and these spheres in turn impart momentum to the spheres that they are in contact with and so on. Hence, the discrete element method (DEM) simulation divides the simulation into two parts: (i) contact or collision between sphere elements, cylinder element and lifter element, and (ii) the movement of the sphere elements because of collisions. In the DEM scheme, the collision is modeled via a contact-force model known as spring-dashpot model and then the Newton Laws of Motion is carefully implemented to follow the motion of the discrete elements. Hence, this physics-based model offers a significant advancement over the empirical models. Since this manuscript is focused on mill power draw, the contact-force model and the calculation of power is briefly described in the following.

The collision between two sphere elements is depicted in Fig. 3, where two spring-dashpots, one in the normal direction and one in the tangential direction are shown.

The normal force, $\boldsymbol{F}_{\mathrm{n}}$, between two particles is given by

$$
\boldsymbol{F}_{\mathrm{n}}=\left(k_{\mathrm{n}} \delta\right) \overline{\boldsymbol{n}}-C_{\mathrm{n}}\left(\boldsymbol{V}_{\mathrm{R}} \times \overline{\boldsymbol{n}}\right) \overline{\boldsymbol{n}}
$$

where $\delta$ is the overlap between the elements, $\boldsymbol{V}_{\mathrm{R}}$ is the relative velocity between the two colliding spheres, $k_{\mathrm{n}}$ is the spring stiffness, $C_{\mathrm{n}}$ is the viscous damping coefficient, and $\overline{\boldsymbol{n}}$ is the normal vector at contact. The tangential force is modeled by the spring-dashpot in the tangential direction as shown in Fig. 3. The tangential force, $\boldsymbol{F}_{\mathrm{T}}$, is given by

$$
\boldsymbol{F}_{\mathrm{T}}=-\min \left[\quad \mu \mathbb{I} \boldsymbol{F}_{\mathrm{n}} \mathbb{I}, \quad\left(k_{\mathrm{t}} \int\left(\boldsymbol{V}_{\mathrm{T}} d t\right)-C_{\mathrm{t}} \mathbb{I} \boldsymbol{V}_{\mathrm{T}} \mathbb{I}\right)\right]
$$




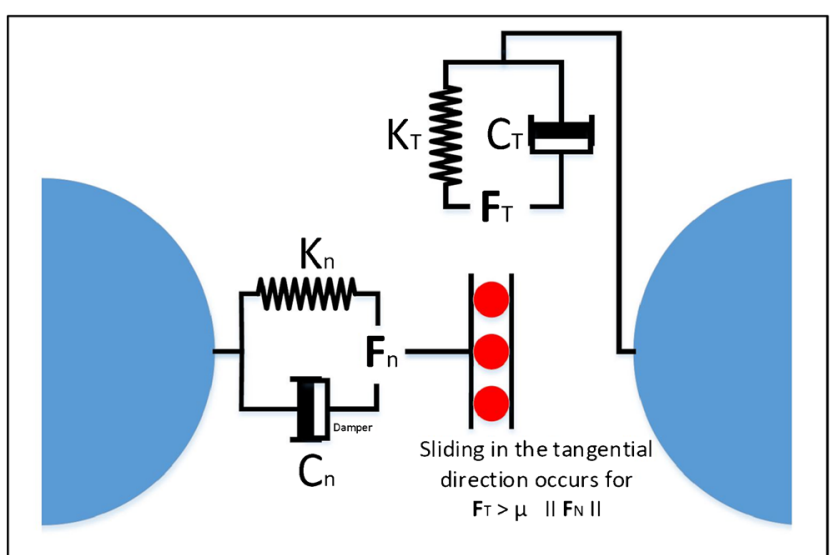

Fig. 3 The scheme of normal and tangential force depicted by springdashpot model

where $V_{\mathrm{T}}$ is the relative tangential velocity, $\mu$ is the friction coefficient, $k_{\mathrm{t}}$ is the tangential spring stiffness, and $C_{\mathrm{t}}$ is the tangential damping coefficient. The spring in both the directions represents the elastic deformation of the colliding spheres, and the dashpot dissipates a proportion of the collision energy. In tumbling mill simulation, the energy expended in all the collisions occurring over a specified time (division by time) represents the net power draw of the mill and hence the damping coefficients are carefully chosen. In fact, the damping coefficient is related to the coefficient of restitution, $\varepsilon$, between the two colliding particles as

$C_{\mathrm{T}}=\frac{2 \ln (\epsilon) \sqrt{K_{\mathrm{T}} m_{\mathrm{eff}}}}{\sqrt{\ln ^{2}(\epsilon)+\pi^{2}}}$

where $m_{\mathrm{eff}}=\left(\begin{array}{ll}m_{1} m_{2} & m_{1}+m_{2}\end{array}\right)$ is obtained from the mass of the two colliding particles $\left(m_{1}, m_{2}\right)$.

In the discrete element simulation of tumbling mills, the energy expended in the collisions between ball to ball and ball to mill shell is summed over one or two full revolutions of the mill to predict net power draw. Correspondingly, in the case of SAG mills, the collision pair between balls, ore particles, mill shell, and liner is summed.

The advantage of DEM simulation over the empirical models is that besides predicting power, it gives a realistic picture of the cascading and cataracting balls and ore particles within the mill. More importantly, DEM can delineate the differences in power draw due to different designs of lifters. The difference in power due to widely different lifter design can be as high as $15 \%$ of total net power draw.

\section{Millsoft-Two-dimensional DEM Simulation of Charge Motion}

The very first software for two-dimensional simulation of tumbling mills incorporated the physics of collision expressed in Eqs. 7-9 [9]. The mill was modeled as a two-dimensional circular slice of width equal to the diameter of the largest particle in the charge mass. Then, the lifter geometry in its exact dimension is imposed on the mill circle followed by the insertion of spherical particles. For two full revolutions of the mill, the simulated collisions and trajectory of particles are computed. Then, the power draw of the two-dimensional slice was computed. The power draw of the full length of the mill was computed by multiplying the computed power by the ratio of the mass of charge in the full length to the mass in the slice. Surprisingly, even though the collisions in the length direction have been suppressed in the simulation, the power predictions are extremely close to the plant data. This software continues to provide valuable insight into the charge motion and power draw to the mining industry [9]. Furthermore, the charge animation provides clear picture of direct collisions against mill shell and the shape of the cascading charge. Hence, this software led to the design of lifters for ball mills and SAG mills.

\section{DEM Computations with Graphic Processing Units}

In the last 5 years, the three-dimensional simulation of tumbling mills is a major step forward. A full 3D simulation of a mill gives much more valuable insights into the dynamics within the mill. To begin with, such a simulation incorporates the collisions in the length direction of the mill besides the planar direction of the mill cross section. It can include the influence of feed and dischargeend lifters on the charge motion. Therefore, the mill power prediction is much more reliable with such simulation. Furthermore, the 3D simulation can also simulate the flow of charge through the grate-plate into the pulp lifter, as well as the dynamics of flow within the pulp lifter. Hence, one can visualize the back flow and the carry-over flow. As a result, the 3D simulation offers the pathway to study liner wear. More importantly, it can quantify the carryover flow and the back flow inherent in pulp lifters in SAG mills. In this manuscript, we present only the power draw prediction of the $3 \mathrm{D}$ simulation.

An emerging trend in the past few years is the implementation of graphic processor units (GPU) for large-scale computations, such as computing with millions of particles in a plant-scale mill. The GPU offers computing performance like that of cluster computing with multiple CPUs, except at a fraction of the cost. GPU computing has been proven for a speed-up of 50× [12] and even $132 \times$ [13] over CPU implementation, for mill charge motion. 
Fig. 4 Hogg and Fuerstenau power predictions of plant data

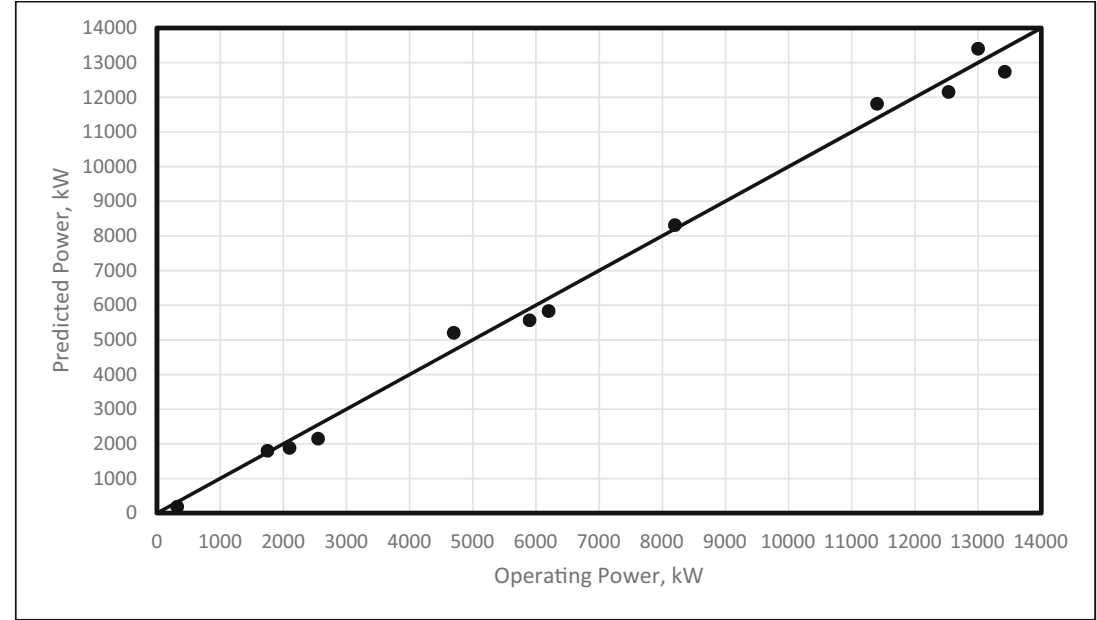

\section{Results and Discussion}

First, we take up the predictive capability of the Hogg and Fuerstenau power equation. Polycorp Ltd., Ontario, Canada, collected data presented in Fig. 4. The data set includes the following mine sites and mills: Copper Mountain, Pretivm Brucejack, Newmont Ahafo Gold Mines, Kinross Chirano Gold Mines, Kinross Tasiast, Escondida operations, Canadian Malartic, Rand Gold Tongon, Loulo \& Kibali operations, Asanko Gold Mines, Suvrudnik Mines, and Barrick Pueblo Viejo operations, etc. The diameter of the mills ranges from 7 to $26 \mathrm{ft}$. Mill length ranges from 10 to $41 \mathrm{ft}$. and the power draw ranges from 300 to $14,000 \mathrm{~kW}$. Figure 4 shows the predicted power against actual operating power. These calculations were done with Moly-Cop Tool adaptation of the Hogg and Fuerstenau power equation (Fig. 4). There is

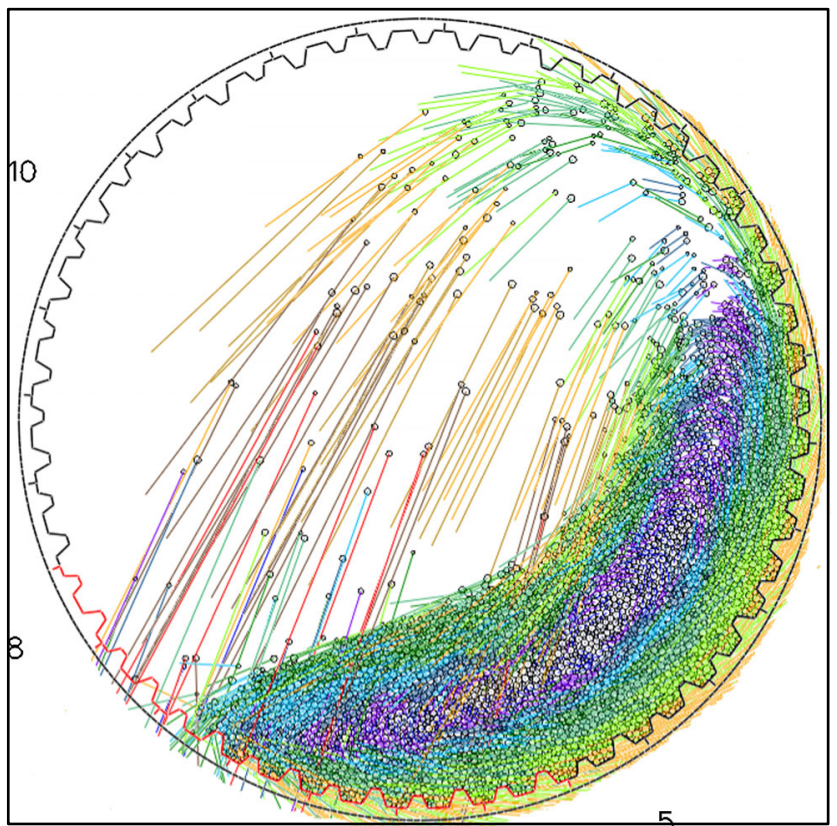

Fig. 5 Millsoft simulation of the $36 \times 26.5$-ft. SAG mill of course some error between plant data and predictions. These are presumably because the plant collects such data over days and weeks and hence the ball filling level and measurements can vary about a few percentage points in between measurements.

\section{Millsoft and Blaze-DEM Mill Simulation Results}

We are furnishing here three mill simulations, which were done with the Millsoft [9] and Blaze-DEM [13-15] codes. The first one is the Hudbay Mines Constancia SAG mill of size $36 \times 26.5 \mathrm{ft}$. The mill is operating at $72 \%$ critical speed and $26 \%$ mill charge volume. The mill is fitted with trapezoid-

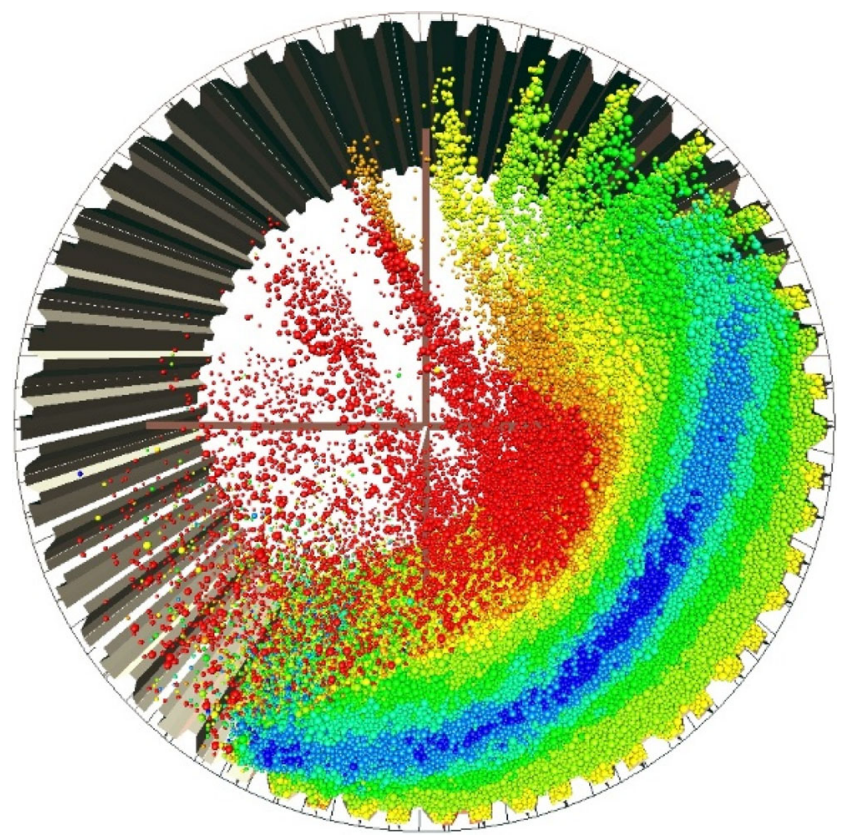

Fig. 6 Blaze-DEM simulation of the $36 \times 26.5$-ft. SAG mill 


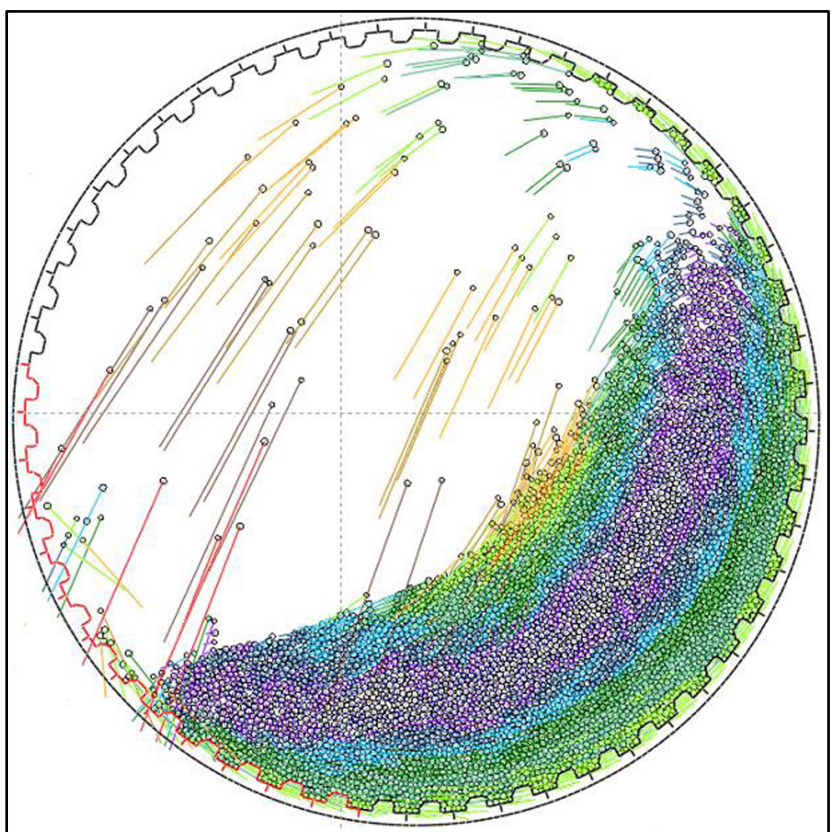

Fig. 7 Millsoft simulation of the $26 \times 40.5$-ft. ball mill

shaped high and low lifters. The operating power draw was reported to as between 13.7 and 15.7 MW. In the Millsoft simulation, 4200 particles were present and the predicted power is 14.1 MW. In the Blaze-DEM simulation, 400,000 spherical particles representing ore and grinding balls were used and the predicted power is 14.3 MW. A snapshot of the charge animation is shown in Figs. 5 and 6.

The second simulation is for the Constancia ball mill of size $26 \times 40.5 \mathrm{ft}$., operating at $74 \%$ critical speed and $32 \%$ ball fill level. The PolyStt ${ }^{\mathrm{TM}}$ lifters were 4 in. high above the shell

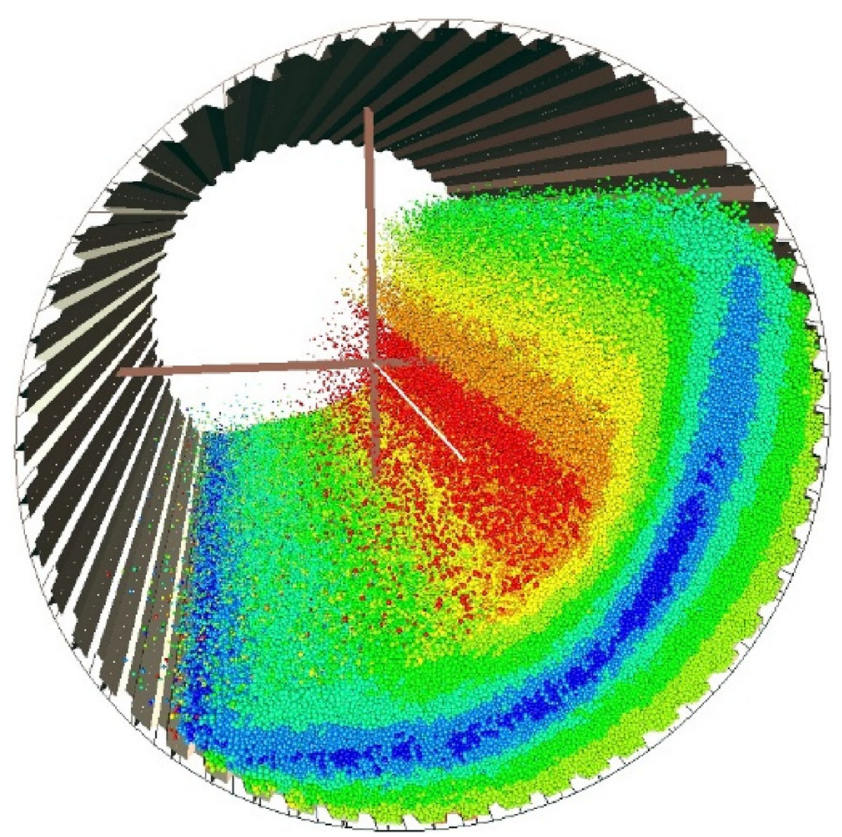

Fig. 8 Blaze-DEM simulation of the $26 \times 40.5$-ft. ball mill

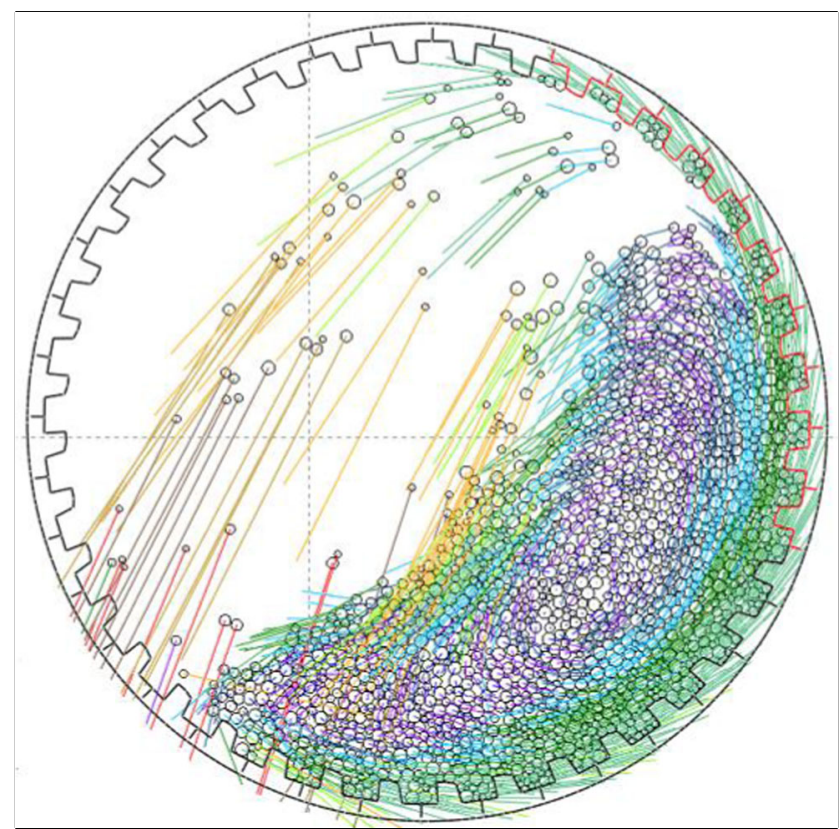

Fig. 9 Millsoft simulation of the $20 \times 32-\mathrm{ft}$. ball mill

plate with the leading edge going into the charge. In the Millsoft simulations, 6033 spherical particles and in BlazeDem 1,600,000 spherical particles representing only the ball charge were used. Figures 7 and 8 show the simulated charge with the codes. Clearly, because of the relief angle of the leading edge, the charge is largely cascading. The operating power is $13.4 \mathrm{MW}$ and the simulated power with Millsoft is 12.9 MW and with Blaze-DEM is 13.1 MW.

The third simulation is that of Tongon operation ball mill of size $20 \times 32 \mathrm{ft}$. operating at $75 \%$ critical speed and $33 \%$ ball

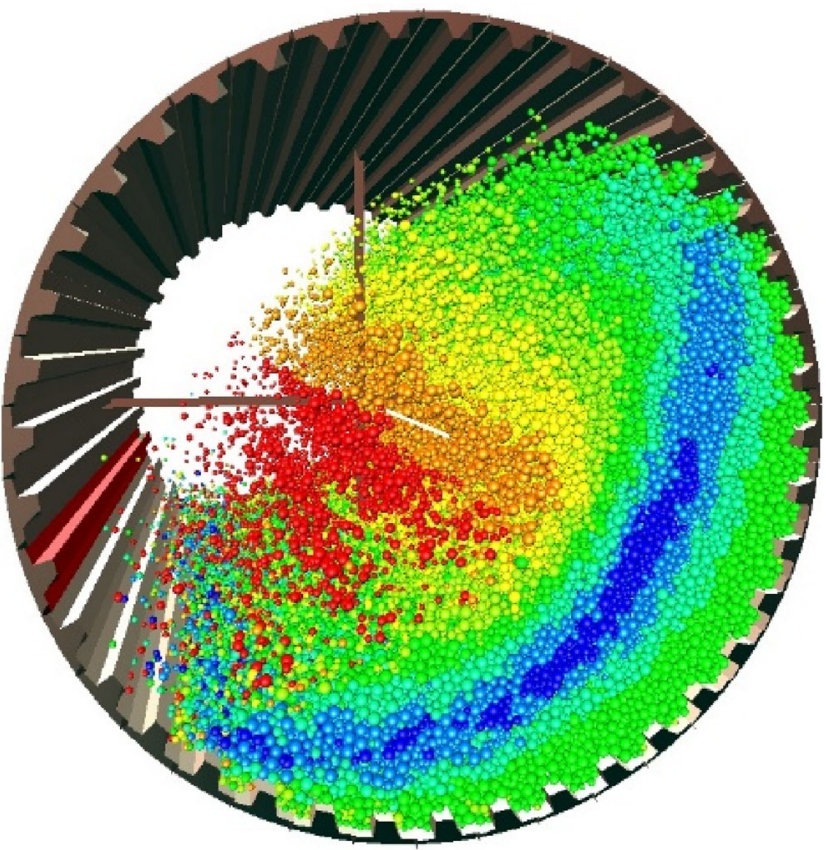

Fig. 10 Blaze-DEM simulation of the $20 \times 32$-ft. ball mill 
fill level. This mill also operates with PolyStl lifters with leading edge inclined into the charge. In the simulations, 1650 spherical particles in Millsoft and 200,000 particles in BlazeDEM, representing only the ball charge, are used in the simulation. Figures 9 and 10 show the charge motion with the two types of simulations. The operating power draw is $8.0 \mathrm{MW}$ and the simulated power draw is $7.2 \mathrm{MW}$ with Millsoft and 7.5 MW with Blaze-DEM.

\section{Conclusion}

The evolution of mill power equations by empirical reasoning and the discrete element method was described in this manuscript. The empirical equation by Hogg and Fuerstenau, although formulated on a simple concept of charge being lifted from the toe to the shoulder of the mill, predicts power very close to operating plant data. It is shown that this equation ball mill power draws very reasonably. However, SAG mill power prediction requires additional development.

The next step is power prediction by the discrete element method-based tumbling mill simulations. Since the density of grinding balls and ore particles is considered in this method, it is equally applicable to ball mills as well as SAG mills. The twodimensional DEM code is easy to use, and it does not require extra computational resources. These codes, when simulating mills with under 10,000 particles, can predict mill power with greater accuracy. For an operating mill, after confirming the power with simulation, the simulation tool can be used for examining the power draw for a variety of lifter designs. Today, such codes are used in North and South America and Australia in the mining industry.

The three-dimensional DEM simulations codes hold great promise. In such simulations, millions of particles are followed in the collision calculations and hence the code execution is computationally intensive. The advances made in GPU computing have made the price of computing hardware for such tasks at par with the price of a laptop computer. The first of such GPU codes, called Blaze-DEM, was shown to produce accurate power predictions in this manuscript. The promise of threedimensional computing is that the transport of material through the grate and pulp lifter to can be simulated. The carry-over flow and back flow inherent to pulp lifter dynamics can be simulated for gaining knowledge for its design. It should be mentioned that these flow regimes are internal to the mill and hence there are no observable measurements in practice.

The future of DEM is in its ability to include the breakage of ore particles in the simulation. However, this is an extreme degree of challenge even for GPU computing. The particle numbers increase by 100 -fold after tens of breakage events. Further, modeling ore bodies whose hardness vary unpredictably across the size spectrum is cumbersome. Yet, such efforts are underway in the past 5 years.

\section{Compliance with Ethical Standards}

Conflict of Interest The authors declare that there is no conflict of interest.

Publisher's Note Springer Nature remains neutral with regard to jurisdiction-al claims in published maps and institutional affiliations.

\section{References}

1. Austin LG (1990) A mill power equation for SAG mills. Miner Metall Process 7:57-63

2. Morrell S (1996) Power draw of wet tumbling mills and its relationship to charge dynamics - part 2: an empirical approach to modelling of mill power draw. Trans. Inst. Mining Metall 105(Sect C):C54-C62

3. Daniel M, Lane G and Morrell S (2010) "Consolidation and validation of several tumbling mill power models," PROCEMIN 2010 Proceedings, Chile

4. Hogg R, Fuerstenau DW (1972) Power relations for tumbling mills. Trans. SME-AIME 252:418-432

5. Sepúlveda JE (2017) "The Hogg \& Fuerstenau power model for AG/SAG Mills: recalibration with an expanded database," PROCEMIN Geomet Conference 2017, Santiago, Chile

6. Herbst JA, Fuerstenau DW (1973) Mathematical simulation of dry ball milling using specific power information. Trans SME 254:343348

7. Herbst JA, Fuerstenau DW (1973) Influence of mill speed and ball loading on the parameters of the batch grinding equation. Trans SME 254:343-348

8. Herbst JA, Lo YC, Rajamani RK (1985) Population balance model predictions of the performance of large-diameter mills. Min Metall Process: $114-120$

9. Mishra BK, Rajamani RK (1994) Simulation of charge motion in ball mills. Part 1: experimental verifications. Int J Miner Process 40: $171-186$

10. Rajamani RK, Mishra BK, Songfack PS, Venugopal R (1999) Millsoft - simulation software for tumbling-mill design and troubleshooting. Min Eng J 51:41-47

11. Cundall PA, Strack ODL (1979) A discrete granular model for granular assemblies. Geotechnique 29:47-65

12. Rajamani RK, Callahan S, Schreiner J (2011) "DEM simulation of mill charge in $3 \mathrm{D}$ via GPU computing." Proceedings of the International Autogenous Grinding, Semiautogenous Grinding and High-Pressure Roll Technology, , Editors: Ken Major, Brian Flintoff, Bern Klein and Kelly McLeod, Vancouver, B.C. Canada

13. Govender N, Rajamani R, Kok S, Wilke DN (2015) Discrete element simulation of mill charge in 3D using the BLAZE-DEM GPU framework. Min Eng 79:152-168

14. Govender N, Wilke DN, Pizette NP, Rajamani RK (2017) Industrial scale particle simulations on the GPU using the Blaze-DEM code, Proceedings of the 7th International Conference on Discrete Element Methods, Book Chapter, , Springer, 1379-1388, 978981-10-1926-5, DOI:https://doi.org/10.1007/978-981-10-1926-5 142

15. Govender N, Rajamani R, Wilke DN, Wu CY, Khinast J, Glassner BJ (2018) Effect of particle shape in grinding mills using a GPU based DEM code. Miner Eng 129:71-84 